\title{
XXIV. On a new membrane in the eye
}

\section{George Hunsley Fielding}

To cite this article: George Hunsley Fielding (1832) XXIV. On a new membrane in the eye , Philosophical Magazine Series 3, 1:2, 113-116, DOI: $10.1080 / 14786443208647846$

To link to this article: http://dx.doi.org/10.1080/14786443208647846

册 Published online: 01 Jun 2009.

Submit your article to this journal 준

LIII Article views: 1

Q View related articles $\sqsubset$ 


\section{[ 113 ]}

XXIV. On a new Membrane in the Eye. By Geonge Hunsley Fielding, Member of the Royal College of Surgeons in London, Member of the British Association for the Advancement of Science, Curator of Comparative Anatomy to the Hull Literary and Philosophical Society, \& c. \&c.*

A CCORDING to the accounts we find in standard ana$A$ tomical works, we are taught to believe that the Pigmentum nigrum of the eye is placed immediately behind, and in contact with the retinat. We are further taught that the colour of this pigment varies greatly in different animals, and that it is of a very light colour, or even wanting, in the nightprowling animals $\ddagger$.

Now, the membrane I have discovered is immediately behind, and in contact with the retina: it presents a fine coloured appearance, which varies in different animals; and is of a very light colour in the night-prowling animals. It is evident, therefore, that what I term a membrane, is usually esteemed to be $a$ pigment. To prove that it is a membrane will be the object of the present paper.

1st. What are the nature and properties of the pigment of the eye? It is a mucous substance combined with carbonacoous matter on which its colour depends $\oint$; it stains white paper; it is removeable by washing $\|$; no known chemical agent has any power either to alter or remove its colour $\pi$.

Take a section of a beast's eye from which the whole of the humours and the retina have been carefully removed: you will find a brilliant spot of coloured surface which was evidently immediately behind the retina. The colour will generally be found to be blueish-green, with frequently a tinge of yellow, the circumference round this spot (which spot varies in size, from occupying three-fourths to less than one-fourth of the bollow of the globe, is of a deep blue.

Now take a piece of white paper and apply it to the blue or green part, you will obtain no stain; wesh it with water, you will not remove the colour, nor stain the water:- here then are two easy proofs that its colour is of a different nature from that of the true pigment of the eye.

But it may be said, that what I am describing is the Tapetum; and if so, unless we are to regard tapetum and pigmentum as synonymous terms (which Cuvier, Richerand; John

* Communicated by the Author:-This paper is an abstract of part of one read before the late Meeting of the British Association for the Advancement of Science, at Oxford.

$\$$ Bell, Fyfe, Monro, Shaw, \&c. \&ce. \$Bell, Fyfe, \&zc. \$Young.

if Bell. T Bichat.

Third Series. Vol. 1. No. 2. Aug 1832 


\section{Mr. G. H. Fielding on a new Membrane of the Eye.}

Hunter, Fyfe, and others seem to do), we shall have two different things occupying the same place, which is impossible. Other anatomists* regard Tapetum and Membrana Ruyschiana as synonymes; and, as Sir Charles Bell justly observes, considerable confusion prevails respecting the precise meaning of the term Tapetum. He, however, defines it to be a pile or fleece laid upon the Membrana Ruyschiana, and states the pigment to be spread upon the tapetum next to the retina, and consequently between it and the retina. It is useless, however, disputing about terms; for all anatomists seem agreed that the pigment is placed immediately behind, and in contact with the retina; and as the part of which I am treating is immediately behind, and in contact with the retina, I apprehend that the following proposition will be the only one $I$ shall have to prove, viz. that the substance placed immediately behind, and in contact with the retina, and known by the name of Pigmentum nigrum, is a membrane, and not a pigment.

1st, We have already seen that it does not stain paper, and is not removeable by washing.--2ndly, Take a section of an eye in which the colours are vivid, place it on the table in a bright light, and fixing your eye on any part, steadily, walk round the table, you will find the colour varies according to the different positions you view it in.-3dly, It presents a bright polished surface, like that of a well-finished mahogany table.4thly, Carefully detach a small portion of this substance, and put it between two thin pieces of glass; it will present a hard and well-defined outline, and on putting the glasses in closer approximation and suddenly relaxing them, you may perceive the substance expand and contract. Again, view this portion by reflected light, you will perceive its usual colour, but with transmitted light you will have a totally different one. In this point it follows Sir Isaac Newton's laws as regards the colours of thin plates. - 5thly, I detached very carefully a small portion of this substance, and placing it between two pieces of fine thin glass subjected it to examination through a fine achromatic Amician microscope by Chevalier; the colour of the portion thus examined, was pale blue by reflected, and reddish-yellow by transmitted light. When placed in the field of the microscope the same change of appearance was observed to take place on viewing it as an opake and as a transparent object. With a power of 800 to the diameter, not only were blood-vessels apparent, but even the globules in those vessels ! and by increasing the magnifying power to its utmost extent, the globules appeared of the size of a very small pin's head. I once thought I could trace nervous filaments, but do not

* Shaw and others. 
feel quite confident on this head.-6thly, It is possible by chemical agents (which, according to Bichat, have not the slightest effect on the pigmentum of the eye) to destroy and restore these colours at pleasure. Take a section of a beast's eye in which the colours are vivid, and dip it into any dilute acid (nitric, muriatic, or sulphuric), you will perceive the colours immediately begin to fade; now dip the portion in cold water, and on taking it out you will find the colours have disappeared; dip it again into the acid, and the colours will reappear as if by the touch of a magic wand; immerse it again in the water, and they will disappear; and so on as often as you please. The same effect is produced by a solution of ammonia. With a pigment this could not occur; and my impression is, that these beautiful colours depend upon the thickness and disposition of the thin laminæ of which by dissection I can prove this membrane to be composed. The cause of the disappearance and reproduction of the colours by chemical agency, I conceive to be merely the effects of heat and cold upon these thin plates, causing alternate expansion and contraction*.-7thly, The true pigment of the eye will be found in the same eyes which possess this brilliant substance; but it will be found behind this part, and most plentiful on the posterior surface of the choroid in connection with the sclerotic membrane. Thus, in the ox, this substance presents a fine blue tint intermixed with green and yellow, and behind it we have the true pigment, of a rich brown; in the sheep it is very similar; in the deer the bright part is pale blueish-white, the pigment a very light brown; in the cat and fox it is a fine golden yellow, and the true pigment a rich black.-8thly, This membrane (as I must term it) is spread over the whole internal surface of the choroides, next to the Tunica Jacobi or external coat of the retina. It varies in thickness, and consequently in the number of its laminæ. It is thickest where the lightest and most brilliant colours are seen, and thinnest in the circumference where it appears of an intense blue colour, and where, no doubt, the colour of the Membrana Ruyschiana underneath affects it. It is very remarkable that neither the extent of the bright surface presenting these varying colours, nor the tint of the colours themselves, are uniform in animals of the same species, - 9thly, Minute injection of the choroid does not affect this membrane.-10thly, I have performed all these experiments on the eyes of the sheep and the ox. As

* Are not these changes of colour more probably referrible to the alterations of texture necessarily induced upon so delicate an organized structure by the application of chemical agents?-EDIr. 
regards the human eye, I have had very little opportunity for investigation; and though $I$ have proved its existence, I cannot say that it ever presented any distinctly coloured appearance. This, however, will be accounted for when 1 come, in another paper, to treat of the effects produced by this membrane, on Vision, and to show the necessity that such a membrane should exist. The name I propose to apply as most descriptive of its appearance, is Membrana versicolor.

XXV. On the Investigation of the Strength of Timber and other Materials, with reference to the recent Experiments and Communications of Mr. Peter Barlow, Jun. By B. Bevar, Esq.

To the Editors of the Philosophical Magazine and Journal. Gentlemen, LLOW me to express my thanks to Mr. Barlow for his
additional experiments, and for his candid reply to my
observations on his first paper. Experiments of this kind,
carefully conducted, are of considerable importance at this
time, and will for many years remain so, and tend to add a
lasting value to your Magazine.

There are many persons who study the properties of timber and other materials, who have not the opportunity of trying experiments on a proper scale; and those who have the means of doing so, frequently want the disposition, even if they possessed the abilities. Communications of this nature are frequently of more advantage to the practical mechanic than the more abstruse and refined theoretical speculations, which always confer great credit and value on your Magazine. Both have their value; but if we estimate their importance by the number of persons likely to be benefited, those which come within the reach of the practical man will be most valued.

To encourage investigations of this nature, was the object I had in view when I made my first remarks on Mr. Barlow's communication, and not to excite any unpleasant feeling in the author. My suggestion that it would be for the benefit of science to observe as far as could be a uniformity in the specification of the properties of timber and other materials, was not intended to imply any censure upon him for adopting an arbitrary number,-which can readily be reduced to the modulus of elasticity by any mathematician,- but to recommend the use of that more generally adopted specification.

As Mr. Barlow affirms he "does not see what advantage 